\title{
Technologies, Opportunities and Challenges of the Industrial Revolution 4.0: Theoretical Considerations
}

\author{
Jan Rymarczyk
}

\section{A B S T R A C T}

Objective: The aim of this article is to identify the impact of the Industrial Revolution 4.0 (IR 4.0) on the production processes of goods and services, their ground-breaking changes, and their potential economic, social, and political consequences.

Research Design \& Methods: The article was based on available literature and online sources. The discussion of the reviewed sources leads to the formulation of three research propositions.

Findings: The technical progress that occurs in modern societies is divided into 4 phases called industrial revolutions. It is assumed that the current phase, i.e. the IR 4.0, began in 2000. It is characterized by the industrial implementation of breakthrough inventions such as the Internet of Things, artificial intelligence, advanced robots, autonomous vehicles, cloud computing, big data, augmented/simulated reality, 3D printing, blockchain, nanomaterials, and digital twins.

Implications \& Recommendations: The sooner the inventions and technological phenomena of the fourth industrial revolution will be implemented by particular economies, the sooner the economic effects of this revolution will emerge in the global economy.

Contribution \& Value Added: The application of breakthrough inventions will cause revolutionary changes in the process of goods production and services, which are synthetically called an intelligent factory and an intelligent supply chain. In addition to the undoubted benefits of - primarily - technical, organizational, and economic nature, many believe that the IR 4.0 will bring threats in the form of rising unemployment, social stratification, threats to cyber security, violations of privacy, ethics, and social norms, a threat of wars based on new inventions and a growing division of the world into rich and poor countries.

\section{Article type: Conceptual article}

Keywords: industrial revolution 4.0; breakthrough technologies; intelligent factory; intelligent supply chain; blockchain; digitization; digitalization JEL codes: L2

Received: 1 September $2019 \quad$ Revised: 2 November $2019 \quad$ Accepted: 10 November 2019

\section{Suggested citation:}

Rymarczyk, J. (2020). Technologies, Opportunities and Challenges of the Industrial Revolution 4.0: Theoretical Considerations. Entrepreneurial Business and Economics Review, 8(1), 185-198. https://doi.org/10.15678/EBER.2020.080110 


\section{INTRODUCTION}

The most important and immanent factor in the development of civilization is technical and technological progress (Upadhyay, 2019). Over the centuries, technological progress determined economic, social, political, and cultural changes that influenced it as well, i.e. they could have favored it or inhibit. In periods when these factors converged, inventions emerged that created breakthroughs in material production processes (Benazzouz, 2018). Modern history distinguishes four such partially interpenetrating and - at the same time - progressive phases called technological revolutions, from the point of view of the level of technological development and technology. They cover a period of slightly over 250 years, which attests to the huge acceleration in the development of science and the implementation of its achievements in production processes (Młody, 2018). Revolutionary changes in this sphere began in the second half of the eighteenth century and were associated with the invention of the steam engine along with its widespread use in transport, metal, and textile industries. Coal and oil have become the main sources of energy for the production of steam. The emergence of a new energy source - electricity - meant a transition to the second industrial revolution in 1870-1914. Electric light, internal combustion engine, and phonograph were inventions representative of this period. A revolutionary change in the organization of factory production was the introduction of an automated production line and assembly line work that enabled mass production, initially in the automobile industry (Wyciślak, 2017). A transition to the third industrial revolution in the 1980s was determined by digital technology, i.e. increasingly common digitization going far beyond the sphere of industry (Petrillo, De Felice, Cioffi, \& Zomparelli, 2018; Prisecaru, 2016). Digital information and communication technologies, the Internet, computers, mobile phones, automation, and robotization found application in many areas of production and social activities. They also form the elementary conditions for the industrial revolution 4.0, whose beginning is conventionally situated in the year 2000. However, unlike the previous revolutions, 4.0 is characterized by much more perfect, wider, deeper, and more complex and systemic applications of mentioned inventions along with the emergence of new breakthroughs. Their combination causes the disappearance of differences between the physical, digital (cyber-physical systems, CPS) and biological (Schwab, 2016a, p. 3) spheres, whose effects predicted by some in the perspective of the next 20 years. In the long run, however, these predictions are close to science fiction, such as the thesis about the elimination of people by super-intelligent robots.

The aim of this article is to identify the impact of the Industrial Revolution 4.0 on the production processes of goods and services, their ground-breaking changes, and their potential economic, social, and political consequences. The article argues that they will be inevitable, because they result from logical civilizational development, determined by challenges related to globalisation processes, and will have both positive and negative consequences, with the predominance of the former.

This short introduction is followed by a brief description of the applied research methodology along with literature review and theory development organized in three interrelated parts related to the conceptualization of the industrial revolution, namely i) technologies as stimulating factors, ii) positive effects and benefits, iii) threats. The article ends with conclusions. 


\section{MATERIAL AND METHODS}

The article is based on available literature and online sources. This is a theory development article, which relies on literature review and desk research.

This conceptual article derives research propositions from literature review and desk research of current business press papers, professional reports, company web pages and blogs, because this subject is relatively new in the theory of economics and international business. We searched through secondary literature with a combination of two screening terms "industrial revolution" and one of the features describe in this article. Many research articles published so far on blockchain originate from computer science. Nevertheless, the focus of this article was business, management, economics. What must be stressed is the fact that many of these sources present similar perspectives, but only this article cites only the most relevant ones.

To conclude, this article should be considered as a conceptual paper, in which literature review and desk research lead to the development of theoretical propositions. As for the scientific approach, this article uses a qualitative design of research, the method of indirect observation, cause-effect analysis, and predictive synthesis, modelling, induction, and description.

\section{LITERATURE REVIEW AND THEORY DEVELOPMENT}

\section{Factors That Stimulate and Constitute the Industrial Revolution 4.0}

The contemporary world economy is shaped by two fundamental phenomena, i.e. globalisation and regionalism. These two megatrends cause fundamental changes not only in the economic but also in the social, political, and cultural sphere (Rymarczyk, 2012, pp. 2741). Along with their progress, the complexity, turbulence, and unpredictability of economic processes increases, so that competition intensifies and new forms appear, such as coopetition, i.e. combining cooperation with competition to obtain a better position on the market. The company's success depends on meeting the challenges dictated by the markets. Companies rely on the ability to produce and provide customers with high-quality products and services in the shortest possible time, tailored to their individual preferences, taking into account the pressure to reduce costs and prices, resource limitations, and environmental protection requirements. This situation requires revolutionary changes in the production process that ensure high innovation, flexibility, efficiency, transparency, close vertical and horizontal integration of activities, and the shortening of the cycle of creating and commercializing effects (Rymarczyk, 2012, p. 44).

The new production paradigm that meets the above criteria, currently in statu nascendi, is called the industrial revolution 4.0. The term is used interchangeably with the term industry 4.0. It can be defined as a comprehensive transformation of the value creation chain, which involves the use of digital production technology via the application of the Internet of Things, artificial intelligence, advanced robots, autonomous vehicles, cloud computing, large data sets, augmented/simulated reality, 3D printing, nanomaterials, distributed databases, and twin technology for artificial intelligence products (see Figure 1).

The Internet of Things (IoT) consists in connecting to the internet of people, objects, products, processes, and systems in the form of a virtual network that enables mutual 
communication in real time (Gubbi, Buyya, Marusic, \& Palaniswami, 2013, pp. 1645-1660). This supports the collection, processing, and transmission of information to optimize the management of the environment, which can mean factories, houses, vehicles, and devices that monitor and control the course of supply, production, transport, and distribution.

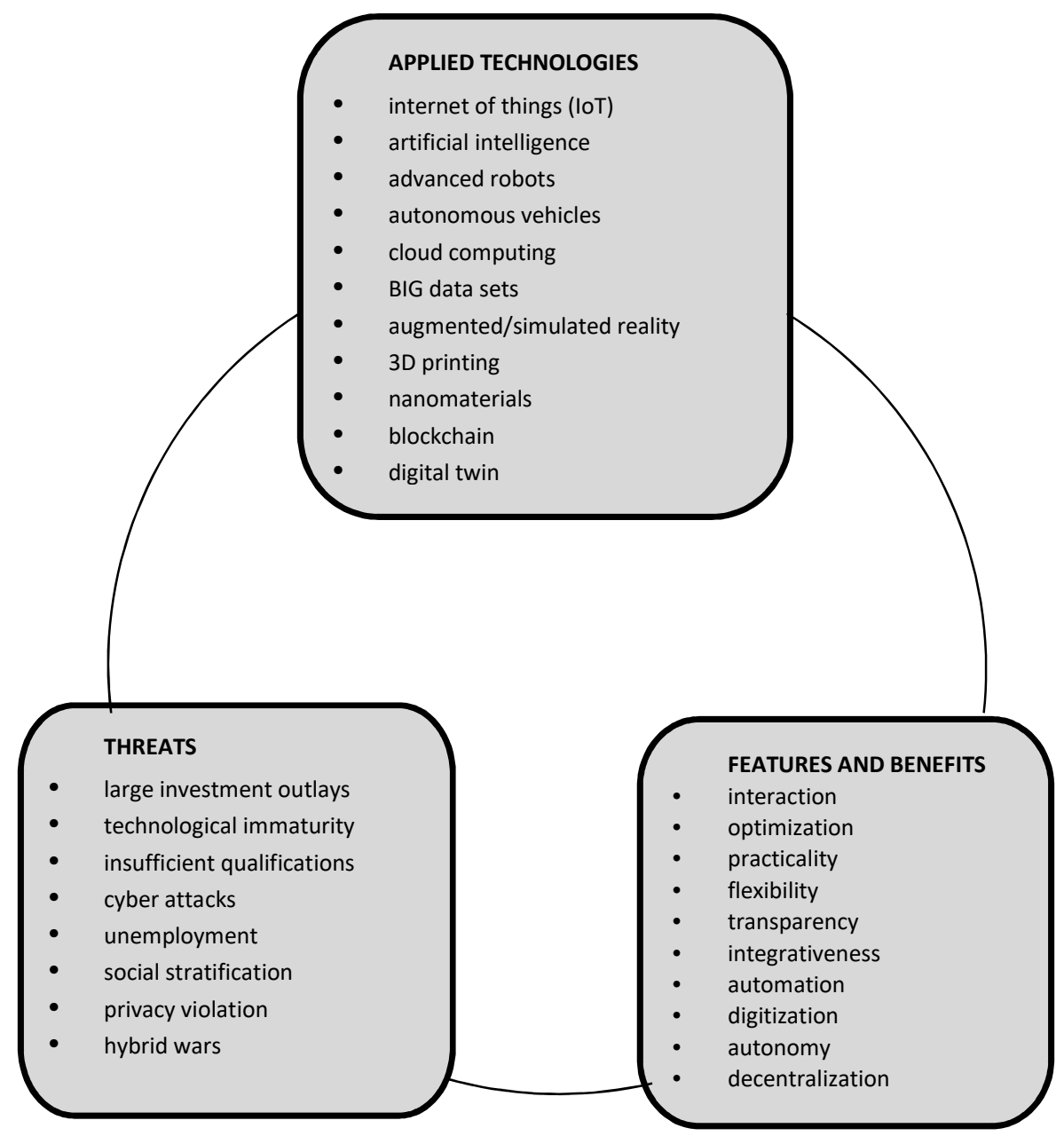

Figure 1. Industrial revolution 4.0 and its threats, benefits, and technologies Source: own elaboration.

Artificial intelligence, also called machine intelligence, means the ability of devices to perceive the environment and autonomously take actions to maximize their chance of success (Shabbir \& Anwer, 2015, pp. 1-9; Warwick, 2012, pp. 31-32, 88-89). Complex algorithms can:

- acquire knowledge and analyze it,

- recognize speech and people,

- recognize letters and images, 
- translate texts,

- learn to make decisions,

- monitor, report, and solve technical problems in production,

- assess the creditworthiness of bank customers,

- plan advertising campaigns,

- create songs and works of art etc.

Artificial intelligence can be applied in all stages of value creation and supply chain, radically changing the business model. It is believed that intensive work on its development may in $\mathbf{2 0}$ years lead to reaching the human level and, in a more distant perspective, even to its surpassing.

Advanced robots are cyber-physical devices that operate based on computer algorithms partially or completely autonomously. They combine artificial intelligence with physical elements (Freeman, 2018; WEF, 2017). Advanced robots have the ability to communicate with people or other robots and correct their activities based on information downloaded from the cloud. They can operate in an unorganized, uncertain, and dangerous environment, change production parameters without need for full reprogramming, and cooperate with people in a safe way. They can be used in virtually all areas of human activity and - above all - they will be the basis for the functioning of an intelligent factory.

Autonomous vehicles (AVs) are a variation of cyber-physical devices that have the feature of mobility. They are used in internal transport within companies, for movement between warehouse and production facilities, in production and distribution. In the future, they will be widely used in public and intercity transport. They will ensure that loads arrive at their destination precisely, safely, and on time (Bonnefon, Shariff \& Rahwan, 2016). The risk of breakdowns and accidents caused by driver errors and fatigue will be reduced. Traffic will become smoother, traffic jams will lose frequency, fuel and electricity consumption will drop, transportation will cease to be one of the factors that contribute most to air pollution and climate change, not to mention its costs will decrease. The mobility of people, including the disabled, will increase and the living conditions in cities will also improve as a result of deglomeration stimulated by the ease of transportation, its accessibility, and cheapness. Moreover, cars, drones, air taxis, and automated boats will be widely used in industry, agriculture, environmental protection, medicine, and services.

Cloud technology is the effect of computing services, servers, databases, networks, software, data storage, and analysis via the Internet (Erl, Mahmood, \& Puttini, 2013, pp. 26-50). There are four basic categories of cloud services, namely the provision of:

- infrastructure (servers, networks, operating systems, virtual machines),

- platforms, i.e. environments for developing, testing, downloading, and managing applications,

- serverless information processing,

- software.

Clouds can be public when services are provided by external providers (e.g. Microsoft Azure), private when cloud resources are used by one company, and hybrid when they combine public and private cloud.

The use of cloud technology eliminates the need to incur capital expenditure for the purchase of hardware and software, which reduces labour consumption associated with 
the performance of Information and Communication Technology (ICT) management activities, provides quick access to desired amounts of ICT resources, and secures its use.

Big Data are sets of data that are too large or too complex to be processed with traditional software applications (Pauleen \& Wang, 2016). The amount of information around the world is unimaginably large and constantly growing. The problem resides in finding, collecting, analysing, sharing, transferring, and protecting relevant data, i.e. managing data. Large data sets are characterized by:

- volume, i.e. the amount generated and produced,

- diversity (text, e-mail, video, audio documents, and their combination),

- variability, i.e. the rate of inflow,

- complexity, i.e. the range of their types,

- veracity, i.e. their credibility.

Information from the analysis of large data sets can be used in production management to increase efficiency, reduce costs, shorten production cycles, reduce losses, determine and prevent the causes of failures, and to increase product innovation. In banking, data sets enable risk minimization, elimination of fraud, and complete an up-todate knowledge of clients' financial standing. In commerce, Big Data can improve transaction management and facilitate customer relationships. In education, it will promote the development of the education system and curricula. In healthcare, Big Data will improve patient service and counting efficiency. Moreover, it will improve the functioning of the public services sector.

Augmented reality is a system that in real time connects the real world - usually in the form of an image - with a virtual, computer-generated world. The effect appears due to the overlap of these two images, which enriches human experience, although it can also be used to simplify/mask certain elements of reality (Jung \& Dieck, 2017). The augmented reality can be obtained with such mobile devices as smartphones and tablets, glasses, helmets and braces, special devices (head-up displays; HUD), contact lenses, and - in the future - also virtual retinal displays (laser images in the human eye). The most popular use of augmented reality is for video games, but the technology has a more serious application in such fields as industrial design and construction, medicine, commerce, navigation, and education. In medicine, augmented reality will allow doctors virtual access to the structure and functions of human internal organs; in commerce, it will support clients in choosing products by multimedia projection in various contexts; in navigation, it will provide better orientation about the location of an object, especially in conditions of limited visibility; in education, it will create interactive training models.

$3 D$ printing involves the production of three-dimensional products from a digital file (Ramya \& Vanapallis, 2016, pp. 398-408). The products come to being due to the application of successive layers of material until the desired effect is obtained in the form of the final product. The materials can be thermoplastics, ceramics, metal powders, composites, glass, or food products. Traditional production first requires the preparation of moulds or dies, which is expensive and labour intensive. 3D printing eliminates this stage, significantly shortening the production cycle and reducing its costs. Based on digital design, products with very complex shapes can be produced, consisting of but a single part, whereas traditional production usually requires the assembly and welding of many elements. This ensures greater strength and durability of 3D-printed products, their more 
accurate reproduction, more flexible design, and material savings. 3D technology is used in prototyping for such works as the production of machine parts, cars, aircrafts, drugs, implants, clothing, footwear, weapons, and for copying works of art or replenishing missing parts. Due to its low price, ease of use, and low transport costs, 3D print will have a special application in the customization of products, i.e. even their individual production, according to consumer preferences near their location.

Nanomaterials are objects or artefacts of very small dimensions measured in nanometres. One nanometre is about one millionth of a millimetre. For comparison, human hair is a million times thicker (Pitkethly, 2004, pp. 20-29). Nanometric particles are found in nature and are created from various products, such as silicon, silver, carbon, titanium, gold, and crystals. They can be used in industry to produce products of low weight, volume, and with extremely high strength and resistance of external influences (e.g. car, aircraft, and other vehicle casings), self-healing materials, i.e. repairing without human intervention, and self-cleaning, i.e. having the ability to remove dirt and bacteria from a surface. In construction, nanomaterials will be added to cement and other building materials to strengthen them. Due to their small size, large electric conductivity, and electromagnetic impulse capacities, they will be extremely useful in electronics. In medicine, nanopharmaceuticals can precisely target specific parts of the human body and destroy cancer cells without damaging others. Nanomaterials also increase the effectiveness of many cosmetics. Moreover, they will find wide application in environmental protection due to their high chemical reactivity. For example, scientists developed with nanomaterials a substance that absorbs carbon from the air and turns it into a useful product.

However, studies show that nanomaterials can be harmful to human health due to their high toxicity. Therefore, their widespread use must take into account this threat and take precautionary measures.

Blockchain is defined as an open distributed book, in which transactions between two parties are recorded in a direct, effective, permanent, and verifiable manner (see Nowiński \& Kozma, 2017). The transactions can also be started automatically on the basis of a special program (smart contracts; laansati \& Lakhani, 2017, pp. 118-127; Dhillon, Metcalf, \& Hooper, 2018, pp. 233-234). There are five basic features of blockchain:

- distributed database. Participating parties have access to a fully decentralized database that records digital transactions. They cannot control them, but they can verify without an intermediary;

- peer-to-peer transmission. Communication takes place directly between peer nodes (links) without a central node, while each node stores and forwards information to all other nodes;

- transparency with pseudonymisation. Each system participant has an insight into all transactions contained in it and has a unique address of more than 30 characters that identifies it. Transactions happen between these addresses;

- irreversibility of records. Once the transaction data has been entered into the system, the record cannot be changed, because it is associated with the preceding one via a string. Each subsequent node contains a shortcut of the previous one;

- computational logic. Digital records in the system mean that transactions can be subject to computational logic and be programmed, i.e. participants can create algorithms and rules that allow automatic transactions between nodes. 
Blockchain will find wide application primarily in the operations of financial market institutions, such as banks, investment funds and stock exchanges (Nowiński \& Kozma, 2017). Besides the financial sphere, practically all industries along with non-profit institutions, governmental organizations, and local governments will be able to use a system that will ensure transaction security, reduce the risk of mistakes, counterfeits, and hacking attacks, not to mention significantly reduce costs by eliminating intermediaries and shortening implementation time.

Blockchain is now used to create cryptocurrencies, of which bitcoin is the most popular. However, in the future, it will probably be the norm to conduct most transactions with blockchain currency, especially the more complex and intelligent transactions.

Digital twin technology involves creating a digital copy of a physical object or process with real-time data to optimize it (Ghobakhloo, 2018; Sieja \& Wach, 2019). This technology mainly uses the IoT, artificial intelligence, and software analysis to create digital simulation models that change along with their physical counterparts. The digital twin is used to monitor, diagnose, forecast, and improve the functioning of devices or the life cycle of products. The basic features of digital twin technology are:

- communication between the physical component and the digital equivalent. Sensors located on a website integrate and transmit information to the digital twin,

- homogenization, i.e. the transmission of information in the same digital form,

- ordinary and autonomous reprogrammability. Physical objects can be reprogrammed by a person through an intervention in the digital twin or without it, based on artificial intelligence,

- digital tracks. Digital technologies leave traces of an object's activity that people can use to remove defects or improve the object,

- modularity. The modular construction of machines and their virtual image allows for quick, automatic, or autonomous module replacement and, thus, their repair, improvement, or programming.

Digital twin technology is most widely used in processing, car, aircraft, space, and renewable energy generation industries. In healthcare, the technology can have a revolutionary character, because a virtual patient can be better diagnosed and, thus, better treated.

\section{Positive Effects of the Industrial Revolution 4.0}

The industrial revolution 4.0 is a phenomenon whose effects are ultimately difficult to predict. Its principal devices (inventions) are usually in statu nascendi, while their wide industrial application may occur over the next several years, if in the so-called meantime there will be no catastrophic phenomena that would prevent its development. We should moreover assume that new, previously unknown inventions may appear that will change our perceptions about the shape of future production and services. An imaginable and achievable holistic effect is an intelligent factory and an intelligent supply chain. The factory of the future is defined as a flexible system that self-improves performance in a wider network, regulates itself, and learns in new conditions, in real time or close to real time, and autonomously launches entire production processes (Burke, Mussomeli, \& Laaper, 2017, pp. 5-8). Intelligent factory is characterized by:

- the interaction of the physical and digital world, 
- optimization, i.e. minimization of material, energy, and human work consumption,

- proactivity, i.e. the ability to anticipate and undertake activities that anticipate problems created by employees and systems,

- flexibility, i.e. adaptation to changes in the production process autonomously or with little intervention from people,

- transparency, i.e. visualization of data on production processes in real time, thus enabling their monitoring and control.

On the other hand, an intelligent supply chain means far-reaching, horizontal, and vertical integration of processes of ordering storage, production, distribution, and customer relations. These will be digital, automatic, largely autonomous, decentralized, and personified, i.e. determined by the individual tastes and needs of customers.

A detailed enumeration of the benefits of these innovative solutions in the production and consumption process includes (Gregor, Medvecky, Matuszek, \& Stefanik, 2009, pp. 124-126):

- better organization and management of the supply chain,

- better planning and monitoring of production processes,

- savings in raw materials, materials, energy, and human labour,

- elimination of downtime and production bottlenecks,

- transparency of manufacturing processes at all stages,

- real-time information availability at all company organizational levels and in all units regardless of location,

- optimization of the number of devices and the use of production space,

- savings in transportation and improvement of logistics,

- shortening and improving the design process, eliminating the creation of prototypes,

- the ability to control processes manufactured from any place in the world,

- the possibility of implementing predictive and prescriptive maintenance strategies,

- the minimization of total production costs,

- the possibility of quasi-closed loop production due to new recycling techniques,

- higher quality, durability, and functionality of products due to the use of new materials and technologies,

- the ability to produce intelligent products,

- the implementation of new, more effective production and consumption models (sharing economy),

- the acceleration of R\&D and innovation processes by creating innovative ecosystems based on global digital platforms and open innovation strategies,

- the production of personalized products according to customer preferences,

- reduction in the risk of 'missed' products,

- flexible response to changes in market demand,

- interaction with customers throughout the entire product development cycle,

- an increase in productivity and efficiency leading to an abundance of supply of goods and services,

- an increase in company competitiveness,

- positive impact on the environment,

- an increase in the attractiveness of jobs and activities performed, 
- an extension of the average age of life and improving people's health,

- raising the level of education and training,

- better way of meeting human needs,

- an increase in the well-being of society,

- more free time.

As visible in the above list, although industrial revolution 4.0 occurs in the sphere of production of goods and services, it will still bring many positive effects in the social and cultural sphere. It will not only change what and how we create but also ourselves and our relations with the environment.

\section{Threats Related to the Industrial Revolution 4.0}

In economics, every benefit comes with a cost, in other words "there is no free lunch." Industrial revolution 4.0 also entails costs, uncertainties, and threats. In the sphere of manufacturing (Schwab, 2016b, pp. 2-8) these include:

- still low level of maturity of the required technologies and their slow development,

- large investment outlays related to the implementation of new machines, devices, and software,

- insufficient qualifications of employees,

- traditionalism and conservatism of top management approach,

- lack of standards, norms, and possibilities of device certification,

- unclear legal situation regarding the use of external information,

- insufficient security of company data networks (threatened by cyber-attacks and industrial espionage),

- uncertainty of achieving the assumed economic effects,

- problems in achieving the appropriate level of vertical and horizontal integration of a unit into the supply chain,

- a threat of redundancy in IT departments of companies,

- shortening the life cycle of products, reducing the benefits of longer life.

In the social sphere, the most serious threats are:

- employment related. Automation and advanced robotics will certainly cause a decrease in demand for unskilled workers employed in assembly and construction works (Lorenz, Rüßmann, Strack, Lueth, \& Bolle, 2018, p. 8). Even employees with medium qualifications cannot feel safe. Many jobs in commerce, finance, insurance, administration, accounting, health care, law offices, and call centres will be closed because devices with artificial intelligence will replace people. On the other hand, people with higher education like engineers, economists, and lawyers - should they lack the knowledge and skills necessary to work in a radically changed environment - will either have to acquire them or will lose their jobs. However, demand will simultaneously increase for IT specialists, programmers, machine designers, software and hardware designers, supply chain designers, planners, energy and resource management managers, robot operators, engineers, technicians, physicists, and mathematicians with specialties related to the functioning, monitoring control, and management of devices and production. They all will be expected to have a combination of technical and non-technical skills, learning abilities and critical thinking in order to easily adapt to the challenges of a complex environment; 
- labour market segmentation will widen the pay gap between high and low skilled workers, which may cause social unrest. Therefore, there is an urgent need for changes in school curricula and for the state and universities to prefer the development of fields of study that offer the best employment opportunities for students. Scholars estimate that $65 \%$ of current primary school students will work in professions that do not yet exist (EC, 2018, p. 9). Generally, owners of intellectual and physical capital of the highest qualifications, top management and shareholders will benefit from industrial revolution 4.0. Income polarization of societies will deepen;

- privacy violation. Industrial revolution 4.0 devices (the Internet of Things, cameras, mobile electronic devices, artificial intelligence) will allow the collection of comprehensive information about people: their location, behaviour, material situation, preferences, abilities, views, education. This information will be required in the personification of products, recruitment of appropriate employees, and security considerations. However, it is easy to cross the boundaries of law in this area, which would lead to violations of dignity and secrecy of persons;

- breach of ethics and social norms in result of genetic manipulation. Scholars presume that this may lead to the selection of a group of people with intellectual and physical qualities exceeding those of all others who cannot afford to finance such experiments; the observed decline of confidence in governments, politicians, businessmen, and the elites in general may deepen as a result of the implementation of industrial revolution 4.0, which may bypass the interests of lower social strata. The history of the Luddite movement - associated with the first industrial revolution - may repeat in a new form in the realities of industrial revolution 4.0.

In the political sphere, the most dangerous seem to be the following threats:

- cyber security. Hacker attacks may be motivated not only by want of financial gain but also political disruption, leading to international conflicts. Many believe that Russian hackers interfered with the election of President Donald Trump in the USA, the revolt of 'yellow vests' in France, and the Brexit vote in the UK. Terrorists can also conduct attacks via industrial revolution 4.0 devices;

- hybrid wars, i.e. combining traditional guerrilla with terrorist and cybernetic operations. Such a war is currently waged by the Russians in Ukraine;

- production of new types of weapons with the use of artificial intelligence, robots, biological engineering, or nanomaterials and the threat of their use in international conflicts;

- a deepening division of the world into rich countries, which will become even richer as a result of the introduction of industrial revolution 4.0, and poor countries, which will be unable to afford the transformation. It is believed that Germany and the USA are currently the most advanced on the road to industrial revolution 4.0. If we assume that one of its consequences will be lower export of jobs from rich to poor countries, i.e. insourcing instead of outsourcing, then the situation among poor countries will deteriorate even further. This will destabilize their political and social situation, create international tensions, and increase migration pressures.

Currently, the above list probably does not exhaust the benefits and threats related to revolutionary changes in the manufacturing process. The list is largely speculative and based on the logic of induction. It will be verified in practice, that is, the shape and course of innovative processes and their effects in the future. 


\section{CONCLUSIONS}

Predicting what will happen in the future and how will it affect the whole of human existence is not only difficult but also fraught with the possibility of partial or complete failure of forecasts. This is proven by the practice of forecasting, sometimes using very sophisticated methods on the border of many fields of science. Will this be the case when assessing future opportunities and threats that will result from the implementation of devices of industrial revolution 4.0? A competent answer to this question will only be possible post factum. Scholars predict that this can happen within the next 10 to 20 years, although it is not certain, because unpredictable catastrophic events may occur that will stop the development of or even annihilate civilization. However, if such bleak scenario does not occur, then the logic of current development indicates a progress of technique and technology that is not only inevitable but also enormously accelerating - it is exponential. The past 20 years have probably seen as many inventions as in the previous 20 centuries. The industrial revolution 4.0 not only uses earlier achievements of science and technology but also creatively develops them by adding new elements, radically changing the way goods and services are produced, with a huge impact on social, cultural, and political spheres of societies. These assumptions are not only speculative but also are based on observations of industrial changes that are already taking place. The aforementioned devices of the industrial revolution 4.0 are already implemented to various degrees in many enterprises, especially in highly developed countries. However, while the expected technical-organizational and economic effects do not arouse much controversy, what is subject to very different assessment are social, cultural, and political issues. These mainly focus on the impact on the labour market and cyber security. Some specialists believe that a social and political Armageddon awaits us as a result of an unprecedented increase in unemployment and polarization of societies. In turn, others believe that new employment opportunities will emerge, while new vocational education will enable job seekers to adapt to the market situation, which means that the effects of industrial revolution 4.0 on the labour market will be neutral or even positive.

We should also consider that the future reality will be shaped not only by revolutionary innovations in industry but also demographic trends, the situation in the natural environment, geopolitics, and new paradigms of social and cultural behaviours. The future and current generations will depend on how we prepare for these challenges ahead of time, and how will we be able to reduce incoming threats.

\section{REFERENCES}

Benazzouz, N.M. (2018). Disruptive Innovation: A Historical Review and Recent Developments. Horizons of Politics, 9(29), 113-130. https://doi.org/10.17399/HP.2018.092907

Bonnefon, J.-F., Shariff, A., \& Rahwan, I. (2016). The social dilemma of autonomous vehicles. Science, 352(6293), 1573-1576. https://doi.ogr/10.1126/science

Burke, R., Mussomeli, A., \& Laaper, S. (2017). The smart factory. Westlake: DeLoitte University Press.

Dhillon, V., Metcalf, D., \& Hooper, M. (2018). Blockchain enabled applications : understand the blockchain ecosystem and how to make it work for you. Orlando, FL: Apress.

Erl, T., Mahmood Z., \& Puttini, R. (2013). Cloud Computing. Boston: Prentice Hall. 
EC (2018). Capitalising on the benefits of the 4th Industrial Revolution. Brussels: European Commission.

Freeman, R.B. (2018). Ownership when Al robots do more of the work and earn more of the income. Journal of Participation and Employee Ownership, 1(1). https://doi.org/10.1108/JPEO-04-2018-0015

Gregor, M., Medvecky, S., Matuszek, J., \& Stefanik, A. (2009). Digital Factory. Journal of Automation, Mobile Robotics and Intelligent Systems, 3(3), 123-132.

Ghobakhloo, M. (2018). The future of manufacturing industry: a strategic roadmap toward Industry 4.0. Journal of Manufacturing Technology Management, 29(6). https://doi.org/10.1108/JMTM02-2018-0057

Gubbi, J., Buyya R., Marusic, S., \& Palaniswami, M. (2013). Internet of Things (IoT): A vision, architectural elements, and future directions. Future Generation Computer Systems, 29, 1645-1660.

lansati, M., \& Lakhani K.R. (2017). The Truth about Blockchain. Harvard Business Review, 95(1), 118-127.

Jung, T.H., \& Dieck, M.C. (2017). Augmented reality, virtual reality and 3D printing for the co-creation of value for the visitor experience at cultural heritage places. Journal of Place Management and Development, 10(2). https://doi.org/10.1108/JPMD-07-2016-0045

Lorenz, M., Rüßmann, M., Strack, R., Lueth K., \& Bolle M. Man and Machine in Industry 4.0. Boston: Boston Consulting Group.

Młody, M. (2018). New production patterns and the future of manufacturing relocation trend in the 4.0 era: The perspective of consumers. International Entrepreneurship / Przedsiębiorczość Międzynarodowa, 4(3), 287-302.

Nowiński, W., \& Kozma, M. (2017). How Can Blockchain Technology Disrupt the Existing Business Models?. Entrepreneurial Business and Economics Review, 5(3), 173-188. https://doi.org/10.15678/EBER.2017.050309

Pauleen, D.J., \& Wang, W.Y.C. (2016). Does big data mean big knowledge? KM perspectives on big data and analytics. Journal of Knowledge Management, 21(1). https://doi.org/10.1108/JKM-082016-0339

Petrillo, A., De Felice, F., Cioffi, R., \& Zomparelli F. (2018) Fourth Industrial Revolution: Current Practices, Challenges and Opportunities. In A. Petrillo, R. Cioffi, \& F. De Felice (Eds.), Digital Transformation in Smart Manufacturing. Rijeka, Croatia: InTech.

Pitkethly, M.J. (2004). Nanomaterials - the driving force. Materials Today, 7(12), 20-29.

Prisecaru, P. (2016). Challenges of the fourth industrial revolution. Knowledge Horizons - Economics, $8(1), 57-62$.

PwC (2014). Industry 4.0 Chancen und Herausforderungen der vierten industriellen Revolution. PwC Strategy \& GmbH. Retrieved from https://www.strategyand.pwc.com/media/file/Industrie-40.pdf on August 31, 2019.

Ramya, A., \& Vanapalli, S. (2016). 3D printing technologies in various applications. International Journal of Mechanical Engineering and Technology, 7(3) 116-127.

Rymarczyk, J. (2012). Biznes międzynarodowy. Warszawa: PWE.

Sieja, M., \& Wach, K. (2019). The Use of Evolutionary Algorithms for Optimization in the Modern Entrepreneurial Economy: Interdisciplinary Perspective. Entrepreneurial Business and Economics Review, 7(4), 117-130. https://doi.org/10.15678/EBER.2019.070407

Schwab, K. (2016a). The Fourth Industrial Revolution. London: Portfolio Penguin.

Schwab, K. (2016b). The Fourth Industrial Revolution: What it means. New York: Crown Publishing Group.

Shabbir, I., \& Anwer, T. (2015). Artificial Intelligence and its Role in Near Future. Journal of LATEX Class Files, 14(8), 1-10. Retrieved from https://arxiv.org/pdf/1804.01396.pdf on September 12, 2019.

Upadhyay, N. (2019). UnBlock the Blockchain. Singapore: Springer. 
Warwick, K. (2012). Artificial Intelligence: The Basics. London: Routledge.

WEF (2017). Impact of the Fourth Industrial Revolution on Supply Chain. Geneva: World Economic Forum. Wyciślak, S. (2017). Implications of digitalization for value chains. International Entrepreneurship I

Przedsiębiorczość Międzynarodowa, 3(2), 37-48.

\section{Author}

\section{Jan Rymarczyk}

Full professor, currently working at WSB University in Poznań (Poland). His research interests include international business and international trade.

Correspondence to: Prof. dr hab. Jan Rymarczyk, Wyższa Szkoła Bankowa w Poznaniu, Powstańców Wielkopolskich 5, 61-874 Poznań, Poland, e-mail: jan.rymarczyk@wsb.poznan.pl ORCID (1) http://orcid.org/0000-003-4701-439X

\section{Copyright and License}

This article is published under the terms of the Creative Commons

Attribution - NoDerivs (CC BY-ND 4.0) License

http://creativecommons.org/licenses/by-nd/4.0/

Published by the Centre for Strategic and International Entrepreneurship - Krakow, Poland 